\title{
Intracoelomic parasitic Sporozoa in the burrowing spatangoid echinoid Echinocardium cordatum: coelomocyte reaction and formation of brown bodies
}

\author{
C. De Ridder \& M. Jangoux \\ Laboratoire de Biologie marine, Université Libre de Bruxelles; \\ B-1050 Brussels, Belgium
}

\begin{abstract}
Echinocardium cordatum frequently harbours in its coelomic cavity the protozoan parasite Lithocystis schneideri. Motile stages of this gregarine (trophozoites and gamonts) may be surrounded by echinoid coelomocytes which show a peculiar transformation of their shape (i.e. each cell develops a single spine-like extension giving a pincushion aspect to the parasite). Encysted stages of the gregarine (gametocysts and sporocysts) are found mostly within brown bodies. Brown bodies are particular mesothelium-covered formations occurring usually in the coelomic cavity of $E$. cordatum. It is suggested that brown bodies naturally originate from detached fragments of mesenteries.
\end{abstract}

\section{INTRODUCTION}

Echinocardium cordatum is infested very often by the gregarine species, Lithocystis schneideri Giard (Cuénot, 1891, 1892; Léger, 1896, 1897; Pixell-Goodrich, 1915). Most of the developmental stages of the gregarine (trophozoites, gamonts, gametocysts and sporocysts) occur within the echinoid coelomic cavity. A very peculiar host reaction was noted by several authors, i.e. the motile stages of the parasite may be covered by coelomocytes which typically are sharp-pointed (Léger, 1897; Pixell-Goodrich, 1915; Brownell \& MacCauley, 1971). The goal of this paper is to characterize the coelomic reactions of $E$. cordatum regarding the main developmental stages of $L$. schneideri.

\section{MATERIAL AND METHODS}

Echinocardium cordatum individuals were collected intertidally on a sandy beach at Le Home-Varaville (Normandy, France). For light microscopy, intracoelomic brown bodies were fixed in Bouin's fluid. They were embedded in paraplast and cut into $5 \mu \mathrm{m}$ sections. Sections were stained with Mayer's hemalun and Masson's trichrome. For EM observations, motile coelomic stages of the gregarine as well as brown bodies were fixed at $4{ }^{\circ} \mathrm{C}$ in a solution of $3 \%$ glutaraldehyde in a sodium cacodylate buffer $(0.1 \mathrm{M}, \mathrm{pH} 7.4)$. They were washed in buffer, postfixed with $1 \%$ osmium tetroxide in the same buffer, and washed again in buffer. For TEM observations, spurr embedding and thin section (LKB ultramicrotome) were performed. Thin sections were then contrasted with uranyl 

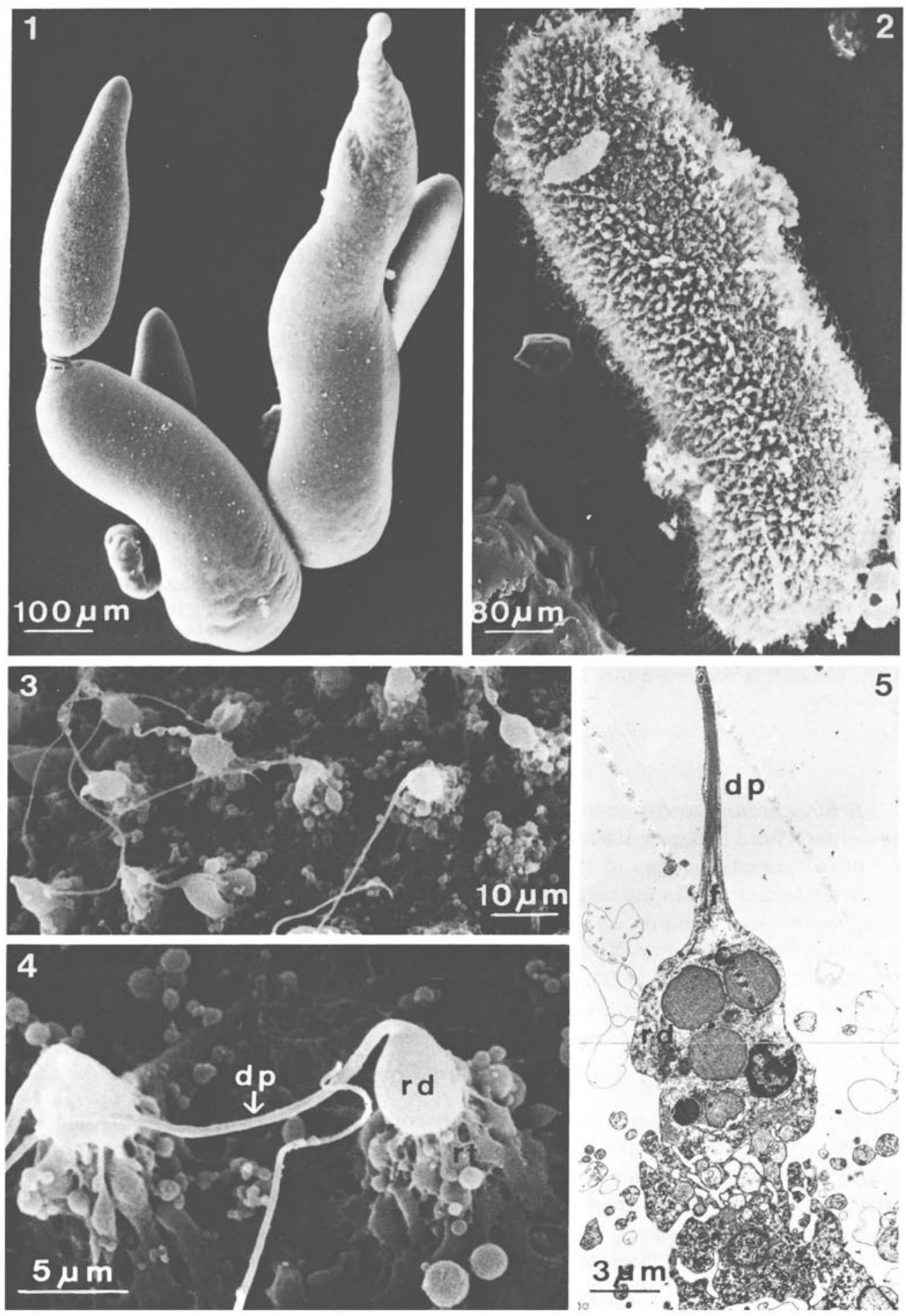

Fig. 1. Gamonts of Lithocystis schneideri in syzygy

Fig. 2. Trophozoite of Lithocystis schneideri covered by sharply pointed coelomocytes

Figs 3-5. Enlarged views (SEM and TEM) of sharply pointed coelomocytes. $d p=$ distal part, $f=$ microfilaments, $r d=$ central round part, $r t=$ basal root 
acetate and Reynold's lead citrate. They were observed on a Philips EM 300 transmission electron microscope at $80 \mathrm{KV}$. For SEM observations, postfixed samples were dehydrated in graded ethanol and dried by the critical point method, using $\mathrm{CO}_{2}$ as transition fluid. They were then mounted on aluminium stubs, coated with gold in a sputter coater and observed with a ISI DS-130 scanning electron microscope at $30 \mathrm{KV}$. Additional SEM observations were carried out on similar samples simply fixed in Bouin's fluid, washed in distilled water and dehydrated in graded ethanol. These samples were dried and coated with gold just like the preceding ones.

\section{RESULTS AND DISCUSSION}

Two types of coelomic reactions occur whether we consider the motile stages or the encysted stages of the parasite. Motile stages are actively surrounded by coelomocytes which tend to wall off the parasite. In contrasts, gregarine cysts are never surrounded by coelomocytes but are found embedded in particular intracoelomic formations called brown bodies.

\section{Coelomocyte reaction}

Trophozoites or gamonts may be "attacked" by coelomocytes (i.e. phagocytic coelomocytes) which tend to surround them. This is the usual reaction occurring in all echinoderms when foreign bodies enter their coelomic cavity. However, in this case parasite-associated coelomocytes show very peculiar transformations. Actually each trophozoite- or gamont-adhering coelomocyte becomes progressively sharply pointed so that the whole parasite looks like a minute pincushion (cf. Figs 1 and 2). Parasiteadhering coelomocytes are rather well differentiated with a basal root-like part extending over the gregarine outer surface, a central round part, and a conspicuous sharply pointed distal part (Figs 3, 4,5).

TEM observations were performed to follow the coelomocyte transformations. An undifferentiated coelomocyte, just about to adhere, is shown in Figure 6. Soon after its adhesion, the coelomocyte adopts a vesicular outline, and piles of membrane-like structures appear here and there over the nuclear envelope (stage 1, Fig. 7). The coelomocyte progressively elongates and a "hood" of clear cytoplasm develops over the nucleus which will be located consequently in the basal half of the cell. At this stage, groups of microfilaments are seen extending from the nucleus towards the apex of the cell (stage 2, Fig. 8). The microfilaments show an axial orientation and are in close contact with a peculiar structure made of piled membranes (stage 3, Fig. 9). The apical cytoplasmic hood progressively tapers while the bundle of axial microfilaments thickens. Piles of membrane-like structures occur in the cytoplasm where they form a kind of cylindrical structure located close to the bundle of microfilaments (stage 4, Fig. 10). Fully transformed coelomocyte (stage 5) is illustrated by Figure 5. It is characterized by a sharp-pointed apical part made of a thick bundle of microfilaments surrounded by the cell membrane.

The presence of sharp-pointed coelomocytes around gamonts has been reported previously (Léger, 1896, 1897; Pixell-Goodrich, 1915; Fauré-Frémiet, 1926). The authors agree that this coelomocyte reaction occurs when parasites lose their motility, i.e. just 

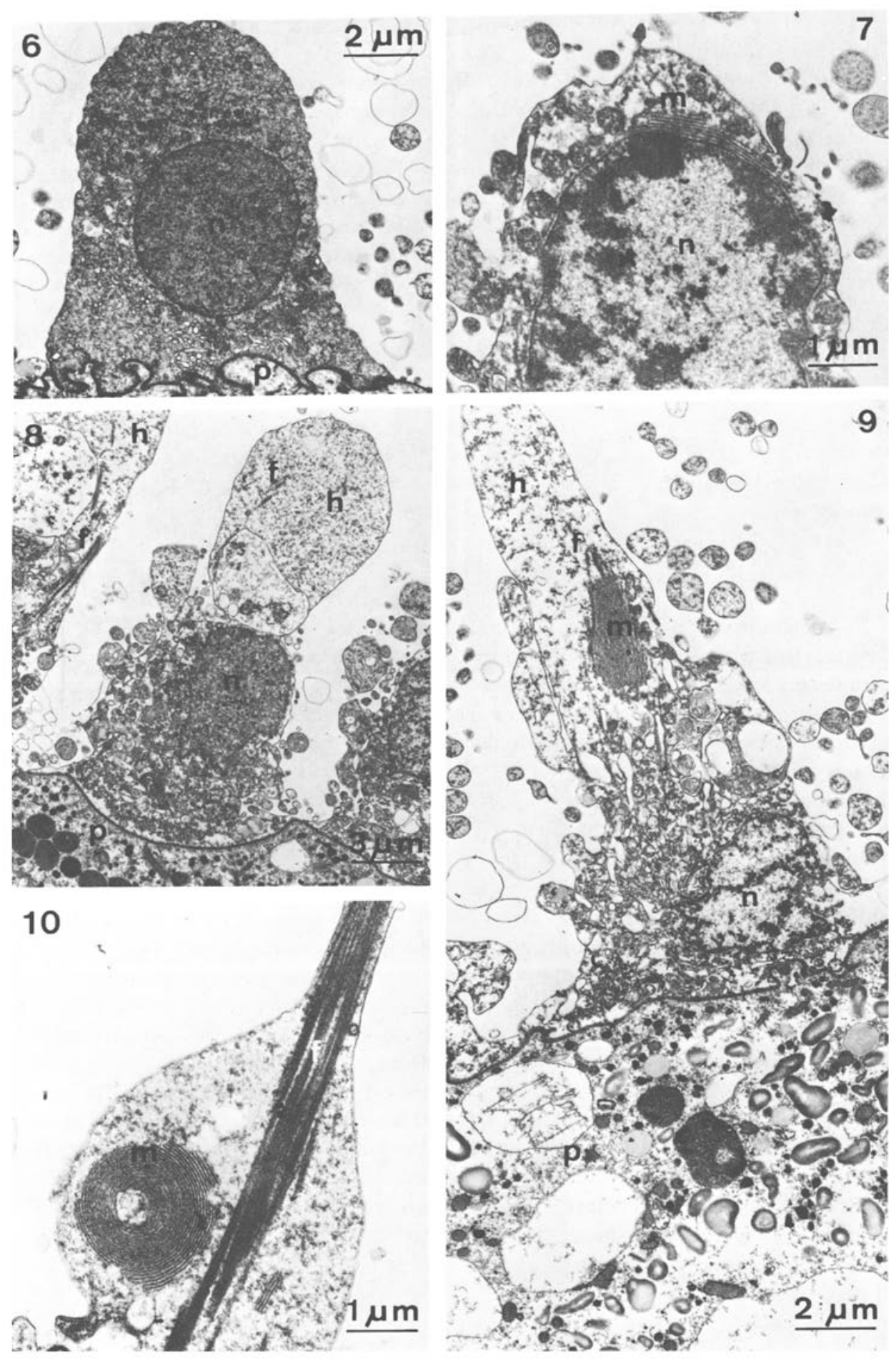

Figs 6-10. TEM-views of coelomocyte transformations: coelomocyte just about to adhere (Fig. 6); stage 1 (Fig. 7); stage 2 (Fig. 8); stage 3 (Fig. 9); stage 4 (Fig. 10). For explanations see text; $f=$ microfilaments, $\mathrm{h}=$ hood of clear cytoplasm, $\mathrm{m}=$ membrane-like structures, $\mathrm{n}=$ nucleus, $\mathrm{p}=$ 
before encystment. According to Léger (1896, 1897), coelomocytes surround every gamont (single or paired) without affecting the normal development of the parasite. In contrast, Pixell-Goodrich (1915) pointed out that only unhealthy parasites are attacked by coelomocytes. Our observations indicate that coelomocyte reaction may occur either before or just after gregarine syzygy, depending presumably on parasite motility. We think that the presence of sharply pointed coelomocytes around trophozoites and gamonts could be a way to prevent gregarine syzygy and thus cyst formation. Trophozoites and non-encysted gamonts walled off by such coelomocytes supposedly degenerate (a suggestion that corroborates Pixell-Goodrich's interpretations).

\section{Structure and origin of brown bodies}

The coelomic cavity of $E$. cordatum contains peculiar, sometimes very conspicuous formations, called brown bodies (Fig. 11). Brown bodies are of various size, being always irregular in shape. They consist basically of clots of pigmented material surrounded by a more or less well preserved cell layer. Intracoelomic cysts of $L$. schneideri (gametocyts and sporocysts) mostly occur within brown bodies. SEM investigations show that a mesothelium surrounds these brown bodies (Figs 12, 13, 14) (cf. report by Brownell \& MacCauley, 1971). Histological sections however indicate that the surrounding tissue layer is relatively complex. It consists of a thin connective tissue layer sandwiched between two mesothelial layers (Fig. 15). This structure is obviously identical to that of the mesenteries partitioning the echinoid coelom. Additional observations show that cyst-containing brown bodies sometimes are "composite" in the sense that they may have several successive mesenteric envelopes, i.e. one main peripheral envelope and several inner envelopes surrounding either single cysts or small groups of cysts.

The morphological study of brown bodies allows a tentative suggestion as to their origin. Authors generally agree to say that the pigmented material within brown bodies results from coelomocyte degeneration (see, for example, Arvy, 1957; Hetzel, 1965). Degenerated coelomocytes occur mostly in the central hemal system (i.e. the axial organ). They are supposedly conveyed to particular hemal "excretory" areas (hemal lacunae of the gut and of the mesenteries) where they accumulate, forming patches of unwanted material (Jangoux \& Schaltin, 1977; Bachman et al., 1980). In E. cordatum such areas occur in mesenteries. Our opinion is that accumulation of degenerating coelomocytes distends the hemal lacunae and breaks down the mesentery. The latter may spontaneously break down at the level of the lacuna. Pigmented materials surrounded by mesenterial envelope are drawn into the coelomic cavity where they form brown bodies.

Gregarine cysts that develop within the coelomic cavity settle and accumulate on mesenteries. The cysts progressively distend the mesentery by their own weight and protrude into the underneath coelomic subcavity (the general coelomic cavity of $E$. cordatum is roughly divided into three superposed subcavities limited by the mesenteries and the loops of the gut). The mesentery presumably breaks down finally, thus allowing the cysts surrounded by a mesenterial envelope to pass into the underneath coelom. The presence of cysts in brown bodies is presumably the consequence of their accumulation on mesenteries whose hemal lacunae were heavily laden with pigmented debris. 

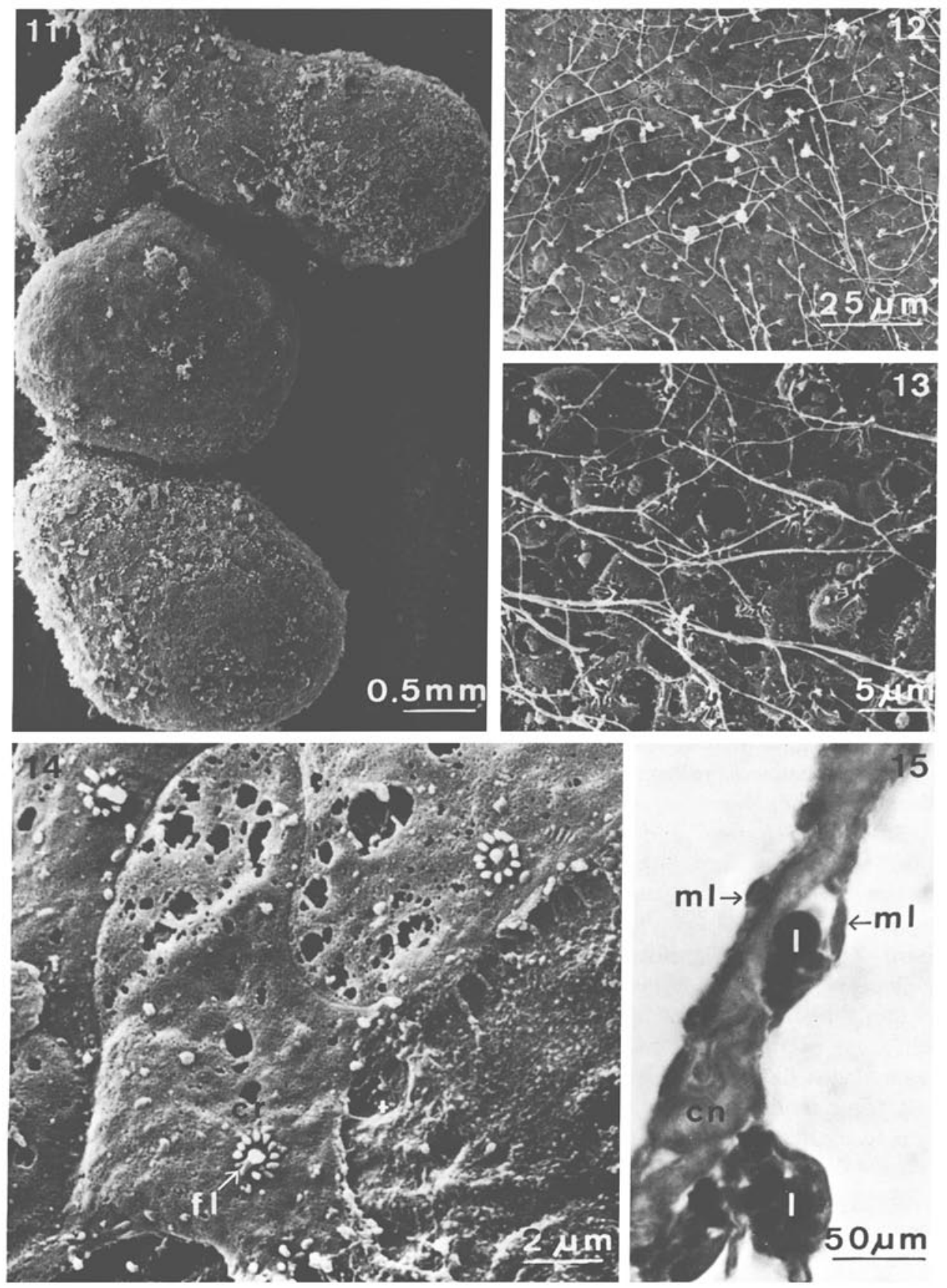

Fig. 11. General aspect of a brown body (SEM view)

Figs 12-13. Enlarged SEM views of the mesothelial cover of brown bodies

Fig. 14. SEM view of altered mesothelial cells from brown bodies; $\mathrm{fl}=$ (broken) flagellum, $\mathrm{cr}=$ collar of microvillies

Fig. 15. Histological section through the mesenteric envelope of brown body; $\mathrm{cn}=$ connective tissue, $\mathrm{l}=$ hemal lacuna, $\mathrm{ml}=$ mesothelium 


\section{CONCLUDING REMARKS}

It is presently impossible to determine to what extent the coelomic reactions of Echinocardium cordatum affect the development of Lithocystis schneideri. One may suppose that the coelomocyte reaction against gregarine trophozoites and gamonts reduce consequently the number of intracoelomic cysts. However occurrence of both attacked and unattacked gamonts in the general body cavity indicates that that reaction has only a partial effectiveness. Embedding of cysts in brown bodies is strictly a passive phenomenon that could occur with any kind of particle falling onto the mesenteries. This embedding apparently does not affect the development of the parasite. As for the pathogenicity of the parasite, we can only say that the investigated echinoids, although being almost always parasitized, had an unaltered life-habit and were perfectly healthy. Investigations are in progress dealing either with the detailed analysis of $L$. schneideri life-cycle and with the frequency of the coelomocyte reaction.

Acknowledgements. We thank Dr. L. De Vos for help and discussion during SEM observations, Drs P. Van Gansen and E. Porchet-Henneré for critical comments, Dr. P. Le Gall for providing facilities at the Marine Laboratory of Luc-sur-Mer (Normandy, France), E. Bricourt and J. Harray for technical assistance.

\section{LITERATURE CITED}

Arvy, L., 1957. Contribution à la connaissance des "corps bruns" des Holothuridae. - C. r. hebd. Séanc. Acad. Sci., Paris 245, 2543-2545.

Bachman, S., Pohla, H. \& Goldschmid, A., 1980. Phagocytes in the axial complex of the sea urchin, Sphaerechinus granularis (Lam.). Fine structure and X-ray microanalysis. - Cell Tiss. Res. 213, $109-120$.

Brownell, C. L. \& MacCauley, J. E, 1971. Two new parasites (Protozoa; Telosporea) from the spatangoid urchin Brisaster latifrons, - Zool. Anz. 186, 141-147.

Cuénot, L., 1891. Protozoaires commensaux et parasites des échinodermes (note préliminaire). Revue Biol. Nord Fr. 3, 285-300.

Cuénot, L., 1892. Commensaux et parasites des échinodermes (deuxième note). - Revue Biol. Nord Fr. 5, 1-22.

Faurê-Frémiet, E., 1926. Différents états morphologiques des amibocytes d'Echinocardium cordatum. - C. r. Séanc. Soc. Biol. 95, 548-550.

Hetzel, H. R, 1965. Studies on holothurian coelomocytes. II. The origin of coelomocytes and the formation of brown bodies. - Biol. Bull. mar. biol. Lab, Woods Hole 128, 102-111.

Jangoux, M. \& Schaltin, P., 1977. Le complexe axial de Psammechinus miliaris (Gmelin) (Echinodermata, Echinoidea). - Archs Zool. exp. gén. 118, 285-303.

Léger, L., 1896. L'évolution du Lithocystis schneideri parasite de l'Echinocardium cordatum. - C. r. hebd. Séanc. Acad. Sci., Paris 123, 702-705.

Léger, L., 1897. Contribution à la connaissance des sporozoaires parasites des échinodermes, étude sur le Lithocystis schneideri. - Bull. scient. Fr. Belg. 30, $240-264$.

Pixell-Goodrich, H. L. M., 1915. On the life history of the Sporozoa of spatangoids, with observations on allied forms. $-\mathrm{Q}$. Jl microsc. Sci. 61, 81-104. 